\title{
Autonomy, problem-based learning, and the teaching of medical ethics
}

\author{
Malcolm Parker University of Queensland, Australia
}

\begin{abstract}
Autonomy has been the central principle underpinning changes which have affected the practice of medicine in recent years. Medical education is undergoing changes as well, many of which are underpinned, at least implicitly, by increasing concern for autonomy. Some universities have embarked on graduate courses which utilize problem-based learning ( $P B L)$ techniques to teach all areas, including medical ethics. I argue that $P B L$ is a desirable method for teaching and learning in medical ethics. It is desirable because the nature of ethical enquiry is highly compatible with the learning processes which characterize PBL. But it is also desirable because it should help keep open the question of what autonomy really is, and how it should operate within the sphere of medical practice and medical education.
\end{abstract}

\section{Introduction}

Three Australian universities (Queensland, Sydney and Flinders) are changing from traditional contentrich medical courses to shorter graduate courses utilising problem-based learning (PBL) techniques (1). One Australian medical school, Newcastle, has employed PBL from its commencement, and is looked on as a model of progressive medical education by many educators within Australia and beyond (2).

One challenge for the new graduate schools will be the integration of medical ethics teaching into the new curricula. While ethics has received more attention in traditional medical courses of late, Queensland, Sydney and Flinders have made a formal commitment to an integrated stream in ethics and professional development. This paper discusses and supports the compatibility of medical ethics and PBL.

I employ two guiding assumptions. The first is that while curricular changes do not occur without the drive and enthusiasm of imaginative medical

\section{Key words}

Medical ethics; autonomy; problem-based learning; medical education. educators, the fundamental motivations for change arise in broad social movements and ideas outside medical education. These movements are critical of reductionist medical practice, the technological imperative and the educational practices which support these. They are essentially ethical motivations; their articulators seek an improvement in things perceived to be bad.

The second assumption is that medicine is currently a primary locus of fundamental questions about the human condition, and about subjectivity and objectivity in ethics and science. As the American sociologist Renee Fox puts it: 'Health, illness, and medicine are central preoccupations in society which have diffuse symbolic as well as practical meaning' (3).

\section{Medical ethics education - background}

The graduate course planners envisage a move away from didactic teaching of detailed basic sciences which results in information overload and functional irrelevance. This is a shift from some of the perceived negative legacies of the Enlightenment and the scientific revolution. With the explosion of Western European science came basic changes in the understanding of human beings, from a transcendent view to a generally secular one emphasizing this life and its possibilities, driven by the engine of science. As the influence of religion waned in the west, science-based medicine developed into one of the codifiers and repositories of truth (4). It gave promise of more extensive life in this world in a culture deserting the idea of life in the next. While radical critics such as Illich (5) have characterized western medicine as a thoroughgoing imperialism, the more moderate view still recognizes the phenomenon of medicalization which has rendered more and more aspects of social and psychological life as medical/scientific problems which can be addressed. In Zola's terms, health tends to become the definition of the good rather than one of the good life's pillars (6).

The culmination of this process is the inclusion of lifestyle and existential difficulties in organized 
psychiatric practice. Some believe these to be beyond the legitimate scope of scientific scrutiny and medical attention. Critics now see scientists, clinicians and psychiatrists as privileged experts whose knowledge of disease becomes holy text, under the guidance of which all disease is to be treated by scientifically proven remedies.

Medicine's normative principles (that life ought to be prolonged and that suffering ought to be reduced), are self-evident in abstracted form. Coupled with the escalation in success in treatment, they produce a passive, cognitive approach to illness - we know as a fact what we are to do in the face of illness, since we have internalized the general values of healing as moral and spiritual facts.

\section{Logical positivists}

While science moved to provide deterministic explanations for the mind, by way of Freudian psychology, academic ethics entered a period commonly seen as having divorced itself from practical ethical questions. Concern centred on whether anything of substance could be said about ethical matters at all. The logical positivists held that the only meaningful things which could be stated were those that were verifiable by observation (7). The ethical counterpart to this position was emotivism that ethical judgments were no more than assertions, and the 'truth' of such assertions was not capable of any kind of verification (8). The determinism of science and the apparent evaporation of any kind of objectivity in ethics were dominant intellectual features of the middle of the century, and they extended their influence into the world of affairs and daily life.

One of the first movements to challenge the dominance of science was the French existentialism of the fifties. Sartre rejected the restraining scientific definitions of the human psyche in favour of a radical freedom where choice and the openness of the future defined the relationship of humans to the world, in contrast to a scientific, deterministic account of human action (9). Existentialist moral autonomy was a logical freedom to act in the absence of any objective standard of moral truth (10) and was an important intellectual stimulant for various protest movements in the sixties and associated moral relativisms. However, while existentialist autonomy eschewed the universality which seems to be a part of morality, it was important in highlighting the idea of choice, which most moral theories share as a necessary element. While human nature seems more than just 'free-floating' choice, existentialism's radical conceptions of human freedom helped ensure the central position of self-determination in the years to come.

Resistance to science also arose in fields such as environmentalism, where pollution, resource depletion, species extinction and other issues became politically sensitive, and where it became important to explore the possibility of an objective basis for ethical claims on people concerning the environment. Similarly, a substantial ethics is required to deal with the problems resulting from the domination of science in the human sphere. AngloAmerican philosophy began to renew its $\bar{C}$ involvement with practical questions of choice and $\frac{C}{=}$ behaviour, and how these questions affected indi- $\frac{\bar{m}}{\frac{\sigma}{\sigma}}$ viduals and society. While medical science increased $₫$ its pragmatic successes, it was apparently at the cost $\cong$ of individual freedom and welfare, as a number of questionable research projects suggested (11). It was also increasingly felt that the success of scientific medicine in prolonging life was becoming a twoedged sword, sometimes resulting in questions about whether the life preserved was really worth living. One practical outcome of this questioning has been the enactment of refusal of treatment legislation in some jurisdictions (12). Such legislation reinforces 0 the legal right to determine when treatment will 을 cease, that is, when it is judged that the value of prolonging one's life is outweighed by the burdensomeness of what life thereby becomes.

It is not surprising that the central intellectual tool which could be brought to bear on these matters of direct human concern was the concept of personal autonomy. Philosophers could be involved î. practical questions since autonomy and the nature persons were problems which had intrigued thinke for centuries. The main ethical theories of the last century examined autonomy in detail. Autonomy was the core concept of human freedom, and as $\mathbb{Q}$ such, was suitable as a conceptual weapon against $\overrightarrow{\vec{F}}$ domination. Moreover, it combined two things $\frac{0}{3}$ which ethical debate had been centrally concerned with: subjectivity and objectivity. Whatever it is, autonomy appears to provide a basis for something substantial. As the existentialists argued, autonomy also captures something we want to believe about $\dot{0}$ ourselves and which we seem to experience, namely our freedom from absolute scientific explanation and predictability.

\section{Dominance of philosophy}

It is fair to say that at the beginning of what are now the recognizable disciplines of bioethics and medical ethics, it was philosophy which 'provided the push toward systemization, consistency, and clarity, as $\mathbb{W}$ progress within medicine increasingly erupted into moral dilemmas' (13). Some have claimed that the dominance of philosophy in medical ethics is no longer a desirable thing, and as a discipline it has $\stackrel{f}{?}$ certainly become much more multidisciplinary in its $\underset{T}{0}$ outlooks and practice (14).

The phenomenon of medical ethics and its $\stackrel{\mathbb{P}}{\mathbb{P}}$ increasing curricular organization can be understood $\mathscr{\complement}$ against this background of the rise of science and secularization, the associated explanation and medicalization of numerous aspects of human life 
with its concurrent loss of anchoring ethical and religious objectivities, and the recalcitrant requirement by human beings for some substantial framework of value. Autonomy appears to establish a source of what is good for a person, all things considered, which replaces those external sources of moral knowledge. It appears to have become the preeminent medical ethical value (15). Future medical practitioners will be educated in a milieu which has taken on board this value, in a more or less conscious way.

Yet medicine wants to explain and predict, in order to serve. Medical ethics is the meeting ground of these viewpoints, since it struggles with the tension between people's best health interests (which are objectively determinable), and best interests, all things considered, (which are subjectively determined) (16). Problem-based learning is effectively structured to take full advantage of this tension.

\section{Medical ethics education - objectives}

There is a consensus concerning the broad goals of medical ethics education (17). Commonly enunciated aims include the following: Physicians should be able to recognize the ethical components of clinical situations, and draw on a fund of skills in ethical reasoning and communication to solve clinical problems (18). They should become aware of their own beliefs, and engage in critical reflection on their own and their colleagues' values and moral commitments (19). They should be equipped with a working knowledge in social, legal and philosophical areas which inform the non-technical side of practice (19).

There is a parallel between these goals and the goals of medical education generally. Graduates should be able to call on a knowledge base and set of practical skills, and be able to defend the resulting practice as scientifically valid, in the performance of the curative and relieving tasks of medicine. But the analogy is at best impure.

Is the defensible set of ethical standards that of a more traditional medicine, or of the more favoured autonomy model of current times? How are patientrights balanced against physician-integrity? Are these trade-offs reflections of moral truth, or are they contextualized to a particular set of cultural and educational circumstances? How will the language and concepts in which the new graduates defend their principles become subjects of challenge in the future? Are the components of any consensus still essentially in service to an individualistic model of medicine, which leaves out important social ethical questions?

These considerations do set medical ethics apart, and make the generic goal of producing good doctors an intriguing process. The PBL approach appears to lend itself best to this elusive task - that of producing good doctors, whose practice remains open to evaluative scrutiny. It could be the best method of achieving two goals. The first is to educate students about ethical issues within medical practice which attract varying levels of agreement (20). The second is to sensitize them to broader ethical questions about medical practice and the institution of medicine.

\section{Ethics and PBL}

I will not attempt a pedagogic defence of PBL. There is evidence that PBL is a superior method for achieving the goals of functional knowledge and practical skills development, and motivation for continued self-directed learning (21). There are also different types of PBL methods and mixtures of PBL and other methods (22). In this paper, I understand PBL to be defined by the following general characteristics:

- Learning occurs in an active way in response to challenges which usually simulate problems which students will meet in their professional work.

- The learning environment centres on the small group tutorial, wherein students and tutor determine learning goals, engage in discussion and critical scrutiny of hypotheses, and agree on task allocation prior to further group sessions.

- PBL fosters the acquisition of skills of selfdirected learning, in contrast to the more didactic approach of traditional courses which focus almost exclusively on presenting current content for committal to memory.

- PBL fosters interdisciplinary learning and emphasizes vertical integration of course material. In medical courses, this means that the traditional distinction between preclinical and clinical blocks is broken down.

PBL techniques have been widely described and practised $(23,24)$. Several features of PBL are congruent with those which characterize ethical enquiry. PBL is problem-driven. Ethical enquiry, even in its more abstract forms, derives from the dilemmas encountered in life. PBL encourages the recognition and toleration of doubt and uncertainty, which are pervasive features of clinical practice. Ethics is a philosophical discipline which has doubt and uncertainty, dispute and argument as its staple diet and modus operandi.

The group discussion arrangements of PBL also sit well with the ways in which ethical enquiry has been conducted. While there is room for individual contemplation and research, active interchange is a stimulus to individuals' creative and innovative thinking, and helps to clarify one's own point of view. The challenge of different perspectives stimulates 'epistemic curiosity', ie, interest in the subject matter which is not just externally motivated (for 
example by the prospect of examination) but which helps develop the truly reflective practitioner (25).

The question of academic expertise in teaching is a thorny problem. Some PBL purists think that tutors should not be subject experts, since subject expertise drives the learning process in the direction of didactism. Traditionalists believe that expertise is a self-evident requirement for the teaching of any discipline. Some teachers think that it is experts with training in PBL methods who will best facilitate learning, since only they can know which facts/theories/perspectives not to 'reveal' in order to stimulate self-directed learning.

\section{Controversies}

These controversies naturally apply to the teaching of ethics. It might be thought that ethical expertise does not exist, and that those professing it will simply indoctrinate students with their particular views. But indoctrination in the ethical sphere would not necessarily be confined to those who profess some kind of ethical expertise - we all have our ethical convictions. And those who claim some ethical expertise are usually not claiming infallible knowledge of moral truth - the claim is rather that of familiarity in the methods of thinking and enquiry concerning ethical questions (26). In any event, the logistics of providing tutors for PBL courses precludes the ability to furnish experts for every student group, and this will apply especially to ethics.

But if there is something to be said for methodological expertise, then such expertise can be called upon during the time spent researching the learning tasks of the PBL sessions. The sessions themselves are best spent in reporting, reviewing, and critically analysing what the experts and students have shared.

The graduate schools will admit students from a broad range of disciplines. Not only will they bring a range of formed ethical beliefs and allegiances, but their undergraduate education will have provided a variety of experiences in humanities and social values. There will thus be disparate content and variable levels of prior knowledge, attitude and belief. Cases which present ethical problems will challenge these structures in a productive way if they are based in real clinical situations or if they are cases which students themselves have had difficulty with. Meeting a variety of views in a friendly atmosphere will stimulate critical scrutiny of students' settled ideas.

Ethical views are usually held with conviction, and convictions are not always open to searching examination. Those trained in science are not necessarily familiar with methods of rational enquiry other than the experimental. Moreover, many of the metaphysical beliefs which underpin ethical systems are seemingly impregnable to any iterative methods at all. The PBL format encourages all participants to express views. PBL as a social structure for learning contrasts with the didactism of traditional educational methods, where more isolated students absorb, memorize and reproduce factual knowledge. With $\Rightarrow$ ethics, there is a real chance of growth and enlighten- $\frac{S}{?}$ ment on the part of both students and tutors.

Another crucial feature of PBL is the extent to which it allows the integration of learning. One of $\frac{\bar{c}}{\frac{5}{\sigma}}$ the chief motivators of change in medical curricula is $\stackrel{\mathbb{Q}}{\Omega}$ dissatisfaction with en bloc segregation of preclinical and clinical science teaching. The increasing $\vec{\circ}$ recognition of the pervasiveness within medical practice of moral concerns suggests that integrating $\vec{\omega}$ ethics into all the other aspects of teaching is a desirable goal. This contrasts with the model of medical ethics teaching which tacks the 'subject' on as an iv ignorable option (27).

Thorough-going integration in all subject areas is attractive because it breaks down barriers perceived 0 as protective of institutional hierarchies which no응 longer serve the educational needs of students. But $\rightarrow$ cautions are expressed, based in perceived threats to $\bigcirc$ departmental identity, funding bases, and the $\frac{\rho}{0}$ dilution of discipline-specific course content. For $\underset{\mathbb{D}}{\mathscr{D}}$ ethics there is an analagous hesitation. Complete integration with clinical cases may provide a functional competence in clinical ethical reasoning ang the commonly used principles employed thereis. But ethics education should not be limited to thas There are links which need to be made between the various case discussions which provide students with a broader view of competing ethical systems, and the concepts they employ. This is not to suggest that $\overrightarrow{\overrightarrow{0}}$ medical students need abstract courses in ethical $\exists$ theory. But there should be a rigorous grappling with the coherences, consistencies and ambiguities with which the task of any ethics, pure or applied, is concerned. Nothing in this suggests that such linking $\overparen{D}$ work cannot also be achieved (and I would claim it can be best achieved) in a PBL format.

\section{Unreflective manner}

There should thus be an exposure to a range of $\frac{D}{O}$ ethical concerns, from the microethical (for example the subtle ethical features of the doctor-patient $N$ relationship) to the broader issues such as resource $N$ allocation which draw in considerations of political $\stackrel{N}{N}$ ethics and to fundamental concerns such as the $\omega$ nature of persons, the sanctity of life, and the limits of institutional power and coercion. Students chal- $\stackrel{\circ}{\subset}$ lenged with assessing the ways in which defensible $\stackrel{\Phi_{+}}{+}$ answers to these problems are sought would be expected to develop an openness to new ideas and a critical faculty which would be important charac- $\frac{D}{\mathbb{D}}$ terological aspects of medical practice. Such aspects $\frac{?}{\mathbb{D}}$ might also be argued to be necessary to any robust $\varrho$ form of professional self-regulation.

Unless the linking units are used, principles such as autonomy will be employed in an unreflective 
manner, ie, they will be internalized passively in the same way that the general values of healing have been. Since autonomy is the principle which has arguably informed the changes bringing about the graduate medical courses, complete integration will cement into place an unreflective, concrete view of autonomy and its primacy. But this is inappropriate, since thought about individuals, society, autonomy, and related matters such as death, responsibility, and health evolves continuously. Conceptions of these things change, and partly because science informs them. (There have already begun in bioethics more critically reflective appraisals of autonomy, even while medical schools and other institutions somewhat belatedly embrace it as the new gold standard (28-30). Doctors are familiar with individuals who appear to be psychologically autonomous, but whose 'inner directedness' prevents them from subjecting their desires to the rational scrutiny of others, including their medical advisers, and of themselves (31)). Without the kind of reflective scrutiny which PBL will afford, medical curricula will presumably need to undergo further painful revisions to catch up to the next moral/ intellectual revolution.

\section{Conclusion}

We understand autonomy in a general sense as selfgovernment. This understanding therefore depends on what account we give of the self. If a self is both subject and object, then science and other methods can co-operate in exploring it. Currently, there is a socio-political emphasis on the subjective interpretation of autonomy, which is an end-result of the idea that we can give no coherent objective account of ethics. In this environment, the only possible ethical objectivity we can hope for is a respect for people's preferences, whatever they may be; this is sometimes described as being able to justify only a 'thin' theory of the good (32).

If we attempt to define what people's preferences could be, the autonomist will accuse us of improper de-limitation of people's freedom. Medical paternalism is supposed to have imposed on people's freedom in this way, by conflating their best health interests (definable) with their best interests all things considered (definable only by the person herself). But while this is an important conceptual distinction to bear in mind, one's best health interests and one's best interests, all things considered, may well coincide, in fact. Thin autonomist theories don't take sufficient account of compassionate exploration of what people's fundamental values really are, and of bringing an influence to bear on what patients decide, in the light of defensible objective assessments of their desires and values. Most doctors remember cases where failure to achieve true insight for the patient meant that neither autonomy nor welfare were well served.
There is a congruence between the PBL mode of learning and a procedural autonomy, where both learning and autonomy are able to admit the influence of the views of others, suitably screened by a mature reflective process. The ideal outcome of the introduction of PBL learning methods in medicine, both in general areas and ethics and professional development, will be a reflective practitioner whose ability to adapt to change, and to live with change and uncertainty, complements a mature kind of patient autonomy which acknowledges not that doctors know best, but that part of their legitimate role involves rational persuasion of those patients with whom they have developed a caring relationship.

Malcolm Parker, MB, BS(Qld), MLitt(UNE), is Senior Lecturer in Medical Education (Ethics and Professional Development) at the Queensland Medical Education Centre, the University of Queensland, Australia.

\section{References}

(1) Teubner J, Saunders N. The emergence of graduate medical schools in Australia. Medical journal of Australia 1993; 159, 5: 293-295.

(2) Hamilton J. A community and population-oriented medical school: Newcastle, Australia. In: White K L, Connelly J E, eds. The medical school's mission and the population's health. New York: Springer-Verlag, 1992: 164-207.

(3) Fox R C. The medicalization and demedicalization of American society. In: Knowles J H, ed. Doing better and feeling worse, health in the United States. New York: Norton, 1977: 21.

(4) Zola I K. Healthism and disabling medicalization. In: Illich I, et al. Disabling professions. New York: Marion Boyars, 1977: 41-46.

(5) Illich I. Limits to medicine. New York: Penguin, 1977.

(6) See reference (4): 51 .

(7) Warnock G J. English philosophy since 1900. Oxford: Oxford University Press, 1969: ch 4.

(8) Hudson W D. Modern moral philosophy. London: Macmillan, 1983: 32-37 and ch 4.

(9) Sartre J P. Being and nothingness. London: Methuen (University Paperbacks), 1969.

(10) Olafson F. Principles and persons. Baltimore: Johns Hopkins Press, 1967: chs 6, 7 and 8.

(11) Beecher H K. Ethics and clinical research. New England journal of medicine 1966; 274: 1354-1360.

(12) For example, Victoria's Medical Treatment Act, 1988.

(13) Clouser K D. Bioethics and philosophy. In: The birth of bioethics [special suppl] Hastings Center report 1993; 23, 6: S10-11.

(14) Philosophy and applied ethics re-examined. Proceedings of the Australian Association for Professional and Applied Ethics, 1993 6-8 August, Newcastle, Australia.

(15) Bartholome W G. A revolution in understanding: how ethics has transformed health care decision making. Quality review bulletin 1992; 18, 1: 6-11.

(16) Young R. Autonomous patients and medical professionalism. Medical journal of Australia 1994; 160, 5: 305-306. 
(17) Miles S $\mathrm{H}$ et al. Medical ethics education: coming of age. Academic medicine 1989; 64: 705-714.

(18) Seedhouse D F. Health care ethics teaching for medical students. Medical education 1991; 25, 3: 231.

(19) See reference (17): 706.

(20) Culver C M et al. Basic curricular goals in medical ethics. New England journal of medicine 1985; 312: 253-256.

(21) Vernon D T A, Blake R L. Does problem-based learning work? A meta-analysis of evaluative research. Academic medicine 1993; 68: 550-563.

(22) Walton H J, Matthews M B. Essentials of problembased learning. Medical education 1989; 23: 551-552.

(23) See reference (22): 542-558.

(24) Schmidt $\mathrm{H}$ G. Foundations of problem-based learning: some explanatory notes. Medical education 1993; 27: 422-432.

(25) See reference (24): 427.
(26) Hare R M. Medical ethics: can the moral philosopher help? In: Spicker S F, Engelhardt H T, ed. Philosophical medical ethics: its nature and significance. Dordrecht: Reidel, 1977: 50-51.

(27) Seedhouse D F. Against medical ethics: a philosopher's $\overrightarrow{\vec{\omega}}$ view. Medical education 1991; 25: 280-282.

(28) Agich G J. Reassessing autonomy in long-term care. Hastings Center report 1990; 20, 6: 12-17.

(29) Savulescu J. Rational desires and the limitation of $\frac{\rho}{\vec{D}}$ life-sustaining treatment. Bioethics 1994; 8, 3: 193202.

(30) Schwartz R L. Autonomy, futility and the limits of medicine. Cambridge quarterly of healthcare ethics, 1992; 2: 159-164.

(31) Feinberg J. Harm to self. Oxford: Oxford University Press, 1986: ch 18.

(32) Engelhardt H T. The foundations of bioethics. Oxford: Oxford University Press, 1986: ch 2. 